\title{
EVALUATION OF THE ROLE OF ANTIMULLERIAN HORMONE (AMH), FOLLICLE STIMULATING HORMONE (FSH) AND ANTRAL FOLLICLE COUNT (AFC) AS A PREDICTOR FOR CYCLE CANCELLATION IN WOMEN DURING ANTAGONISTIC PROTOCOL FOR ICSI
}

\author{
By
}

\section{Buthiena Khalil Gerriw, Ismail MohamedElfortia, Hanan El-Jabu, Nahla IbrahimBetelmal*}

\begin{abstract}
National Infertility Center Assisted Reproductive Technique Unit, Faculty of Medicine, Misurata University Libya, and Statistical Researcher, Glasgow Caledonian University, Glasgow, UK*
\end{abstract}

\begin{abstract}
Background: Abnormal ovarian reserve test (ORT) results and, woman age are strong predictors of cycle cancellation during assisted reproductive technique. Use of Anti- Mullerian hormonecan helps to decide cycle cancellation during ICSI at different age groups.

Objectives: To evaluate the role of biomarkers (Anti-Mullerian, FSH hormones) and antral follicle count, as predictors of cycle cancellation in women during antagonistic protocol ICSI.

Participants and Methods: Retrospective study of 491 cases received ovarian stimulation for ICSI by antagonist protocol during the period of 2013-2014, at Misurata National Infertility management center was conducted. Candidate characteristics were collected, endocrine data, collected during early follicular phase (D3) of the stimulating cycle (FSH, AMH). Sonographic data were collected during early follicular phase by counting antral follicles in both ovaries, and after stimulation. An antagonist protocol was applied to all patients of different age groups.
\end{abstract}

Results: Cycle cancellation occurred in $24.64 \%$ of stimulated patients. The mean age for the patients with cancelled cycles was higher than the age of those with completed cycles, and $16.7 \%$ got pregnant. The age of the women who got pregnant was lower than the age of non-pregnant women. AMH was a fair test for the discrimination between cancelled and completed cycles with a highly significant value. When investigating the three age groups, AMH was a fair test for the discrimination between cancelled and completed cycles for age group $>39$ years.

Conclusion: Serum AMH levels can be used as a fair predictor test for cycle cancellation especially in older age group patients. Its use can help to individualize treatments protocols and counselling in different age groups. Counselling plays an important role in addressing psychological issues discussing the risks of cycle cancellation due to costbenefit, and treatment options to ensure maximal therapy benefits and outcomes.

Correspondence: Bouthinagreiw@gmail. Research Center, National infertility center, Assisted Reproductive Technique Unit,Misurata Libya.

Key words: Anti-Mullerian hormone, cycle cancellation. different age groups, antagonistic protocol ICSI. 


\section{BUTHIENA KHALIL GERRIW et al.}

\section{INTRODUCTION}

Optimal ovarian response is a key part of controlled ovarian stimulation (COS) procedures. The ability to predict ovarian reserve is crucial to obtain an adequate response and an optimal outcome from assisted reproductive technologies (ART), and offers the possibility of tailoring COS protocols for each individual patient. ( $\mathrm{La}$ Marca and Sunkara, 2014).

It is well acknowledged that some named predictors of ovarian reserve markers including serum basal follicle stimulating hormone (FSH) concentration, antral follicle count (AFC) and serum antimullerian hormone (AMH) concentration can be used as predictors of ovarian responses to gonadotropin stimulation during ICSI treatment ( $\mathrm{Li}$ et al., 2013).

Although, some reports have shown a poor predictive performance of these markers, other reports indicate these predictors can be used accurately for estimation of success rate before initiation of the therapy process (Broer et al., 2009). The number of antral follicles as measured by vaginal ultrasound was even superior to basal day 3 FSH and BMI for predicting the number of oocytes retrieved for IVF ( $\mathrm{Ng}$ et al., 2000). Ovarian reserve can be considered normal when stimulation by exogenous gonadotropins will result in development of 5-12 follicles from both ovaries and the retrieval of the same number of healthy oocytes (Broekmans et al., 2012).

AMH is specifically expressed in granulosa cells of small growing follicles, and highest expression is observed in preantral and small antral follicles. $\mathrm{AMH}$ is no longer expressed by mural granulosa cells during the FSH-dependent stages of follicular growth, nor is it expressed in atretic follicles (Van Houten et al., 2010). However, expression persists in the cumulus cells of pre-ovulatory follicles. $\mathrm{AMH}$ has also been suggested to exert a physiological effect on antral follicles in the human ovary before final selection. It has been suggested that AMH may exert a physiological role in down-regulating the aromatizing capacity of granulosa cells until the time of follicular selection (Kelsey et al., 2011). In comparison with other ovarian reserve assessment tests, $\mathrm{AMH}$ is characterized by several advantages. AMH levels are stable throughout the menstrual cycle and between cycles andcan be measured at any day of the cycle. AMH levels are not affected by other hormonal variations, including the use of oral contraceptives (Bentzen et al., 2012). AMH is not detected in women until puberty and reaches its highest levels at age 24.5 years. With increasing age, the number and quality of oocytes decline. Accordingly, the AMH level also declines and is lowest at menopause; later, it is not detected at all (Ubaldi et al., 2005).

Basal follicle stimulating hormone (FSH), provides an indirect marker as its level willincreasewith advanced age. High level of FSH represent small cohort size. Basal FSH levels of less than 10 to 12 milli international units $/ \mathrm{mL}$ are considered normal (Kligman, and Rosenwaks, 2001).

There are not enough studies assessing the predictive value of these markers in different age levels since some ovarian reserve markers may have different accuracy in different ages. 
The aim of the current study was to examine the predictive value of $\mathrm{AMH}$, FSH, and AFC to predict cycle cancelation in ICSI cycle in population with different age groups.

\section{PARTICIPANTS AND METHODS}

A retrospective cohort study of women (700 cases) receiving treatment during the period of 2013-2014, for ICSI at Misurata national infertility management center, Libya toevaluate the role of biomarkers(Anti-Mullerian, $\quad$ FSH hormones) and antral follicle count, as predictors of cycle cancellation in women during antagonistic protocol ICSI.

Women between the ages of 20-45 years were included in this study. Only 491 cases were involved in the study as women with history of previous ovarian surgeries, polycystic ovarian syndrome and endometriosis were excluded.

Division of women was into three categories according to age, from 20-29 years, 30-39, and older women from 4045 years. AMH, FSH and AFC can be used as predictors of cycle cancellation.

- AMH measurement was done and quantified in the morning of day 3 of the menstrual cycle by the immunoassay supplied by Diagnostics systems laboratories (DSL) (a Roche Hitachi) that has a sensitivity of 0.043 $\mathrm{pmol} / \mathrm{l}(0.006 \mathrm{ng} / \mathrm{ml})$. AMH in $\mathrm{pmol} / \mathrm{l}$ units $(7.18 \mathrm{pmol} / \mathrm{l}$ of $\mathrm{AMH}$ is equivalent to $1 \mathrm{ng} / \mathrm{ml}$ of $\mathrm{AMH}$ ).

- FSH was measured in the morning of day 3 of the menstrual cycle. It was reported in $\mathrm{mIU} / \mathrm{ml}$, by Electro Cheiluminescence Immuno using
Access ${ }^{\circledR}$ technology (Beckman Coulter Inc).

- The AFC and normal anatomy of pelvic organs were determined by performing transvaginal ultrasonography (TVS). The main outcome measures were the number of retrieved oocytes.

\section{STIMULATION PROTOCOL}

Antagonist protocol was applied on study population. On day 2 of the cycle, the treatment with gonadotropin human menopausal gonadotropin (menogone) was fixed daily in dose of 250 IU $\mathrm{HMG}$ (Menogon, Ferring, Kiel, Germany). The ovarian response monitored by transvaginal US from the sixth day of stimulation and repeated every other day.Gonadotropin doses were introduced. Antagonist (Cetrorelix; Serono) started $0.25 \mathrm{mg}$ daily on day 6 of stimulation cycle. When at least three follicles larger than $18 \mathrm{~mm}$ or more were observed, 10000 IU of HCG (Pregnyl, Organon UK) was administered intramuscularly. Thirtysix hours later, follicles were collected by transvaginal ultrasonography-guide under general anesthesia. The number of retrieved oocytes was recorded. Ovarian response was defined.

Poor response (Cycle cancellation) in our study: The presence of at least two of the following characteristics: Advanced maternal age $\geq 40$ years, three or fewer oocytes on retrieval, low $\mathrm{AMH}$, in the present study we took 2 pmoll as cut off level of $\mathrm{AMH}$ according to literature (Calamera et al.,2013). Average response: OCR of 4-15 and hyper response: OCR of $>15$.

After fertilization of oocytes with sperm in the laboratory, embryos were 
transferred. Serum $\beta$-hCG levels were measured 12-14 days after transfer to assess conception. All pregnant women received Cyclogest suppository (Alpharma, Barnstaple, UK) 400 mg daily until 12 weeks of gestation to support luteal phase.

\section{Statistical analysis:}

During data analysis, age and biomarkers levels (AMH, FSH, and AFC)were presented as mean, standard deviation, and range. The Mann-Whitney $\mathrm{U}$ test was used for comparison of the non-parametric data.Sensitivity was defined by the association of lower hormone level with cancelled cycles, while specificity was defined by the association of higher hormone levels with completed cycles or completed cycles and pregnancy. An area from 0.9 to 1 represents excellent test, from 0.8 to 0.9 good test, from 0.7 to 0.8 fair test, from 0.6 to 0.7 poor test, and from 0.5 to 0.6 fail test. Logistic regression analysis was used to assess the association of AMH and other variables with cycle cancellation. Results of all tests were considered significant if its $\mathrm{P}$ value was $<0.05$.

\section{RESULTS}

The mean age of our participants was 37.68 ( $\mathrm{SD} \pm 4.73$ ). Out of the 491 cases studied 121 patients $(24.64 \%)$ were cancelled, and 82 cases were found to be pregnant $(16.7 \%)$. The mean age for the patients with cancelled cycles is higher than the age of those with completed cycles $(p=0.0075)$ statistically significant. Also, the age of the women who got pregnant is lower than the age of nonpregnant women $(p=0.0059)$ (Table 1).

\section{Table (1): The age in the studied cases}

\begin{tabular}{|c|c|c|c|c|}
\hline Cases & No. & Mean \pm SD & Range & $P$ value \\
\hline All cases & 491 & $37.68+4.73$ & $20-45$ & \\
\hline Cancelled & 121 & $38.51 \pm 4.84$ & $20-45$ & \multirow{2}{*}{0.0075} \\
\hline Completed & 370 & $37.41 \pm 4.67$ & $24-45$ & \\
\hline Non-pregnant & 288 & $37.71 \pm 4.76$ & $24-45$ & \multirow[b]{2}{*}{0.0059} \\
\hline Pregnant & 82 & $36.35+4.18$ & $24-45$ & \\
\hline
\end{tabular}

The AMH level shows mean \pm SD $(2.46 \pm 2.36 \mathrm{pmol} / \mathrm{l})$ and the range $(0.1-$ $19.4 \mathrm{pmoL} / \mathrm{l})$ of all cases. Cancelled cycles had a lower level than completed cycles $(\mathrm{P}=0.001)$, and non-pregnant had non-significant lower level than pregnant
$(\mathrm{P}=0.0562)$. The younger age group had higher AMH level $(p=0.001)$. The FSH level shows mean \pm SD (8.24 \pm 3.86 $\mathrm{IU} / \mathrm{ml})$ and the range $(0.24-33.72)$ of all cases. Cancelled cycles had a higher level than completed cycles $(\mathrm{P}=0.005)$, and 
non-pregnant had higher level than pregnant $(\mathrm{P}=0.0201)$. The difference in the FSH level between younger and older age groups is insignificant. The AFC level shows mean $\pm \mathrm{SD}(5.42 \pm 3.95)$ and the range $(0-20)$ of all cases. Cancelled cycles had a lower level than completed cycles $(\mathrm{P}=0.001)$, and non-pregnant had lower level than pregnant $(\mathrm{P}=0.0084)$. The younger age group had higher AFC ( $\mathrm{p}=$ 0.001) (Table 2).

Table(2): The AMH, FSH, and AFC levels in the studied cases

\begin{tabular}{|c|c|c|c|c|c|c|c|c|c|c|}
\hline Cases & No. & $\underset{\text { Mean+SD }}{\text { AMH }}$ & Range & $P$ value & $\begin{array}{c}\text { FSH } \\
\text { Mean } \pm \text { SD }\end{array}$ & Range & $P$ value & $\begin{array}{c}\text { AFC } \\
\text { Mean } \pm \text { SD }\end{array}$ & $\begin{array}{l}\text { Rang } \\
\text { e }\end{array}$ & $\begin{array}{c}\mathbf{P} \\
\text { value }\end{array}$ \\
\hline All cases & 491 & $2.46 \pm 2.36$ & $0.1-19.4$ & & $8.24 \pm 3.86$ & $0.24-33$ & & $5.42 \pm 3.95$ & $0-20$ & \\
\hline Cancelled & 121 & $1.51 \pm 1.18$ & $0.1-6.2$ & & $9.63 \pm 5.15$ & 1.6-33 & & $4.09 \pm 3.22$ & $0-20$ & \\
\hline Completed & 370 & $2.77 \pm 2.56$ & $0.3-19.4$ & 0.0001 & $7.78 \pm 3.21$ & $0.24-26$ & 0.0005 & $5.86 \pm 4.07$ & $0-20$ & 0.0001 \\
\hline $\begin{array}{c}\text { Non- } \\
\text { pregnant }\end{array}$ & 288 & $2.70 \pm 2.63$ & $0.3-19.4$ & & $8.02 \pm 3.32$ & $0.24-26$ & & $5.57 \pm 4.0$ & $0-20$ & \\
\hline Pregnant & 82 & $3.01 \pm 2.3$ & $0.5-11.7$ & 0.0562 & $6.92 \pm 2.62$ & $1.3-17$ & 0.0117 & $6.86 \pm 4.18$ & $0-18$ & 0.0084 \\
\hline Age $20-29$ & 30 & $4.32 \pm 4.34$ & $0.8-19.4$ & & $7.92 \pm 3.23$ & $0.24-14$ & & $8.33 \pm 4.55$ & $0-18$ & \\
\hline Age 30-39 & 266 & $2.63 \pm 2.36$ & $0.2-16$ & & $8.09 \pm 3.67$ & $0.57-23$ & & $5.97 \pm 4.16$ & $0-20$ & \\
\hline Age $40-45$ & 195 & $1.95 \pm 1.66$ & $0.1-11.7$ & & $8.48 \pm 4.19$ & $1.6-33$ & & $4.23 \pm 3.09$ & $0-15$ & \\
\hline
\end{tabular}

AMH was a fair test for the discrimination between cancelled and completed cycles with a highly significant value (ROC-AUC 0.7103, 95\% CI 0.65624-0.76434). When investigating the three age groups, AMH was a fair test for the discrimination between cancelled and completed cycles for age group >39(age group 3) (ROC-AUC 0.7434, 95\% CI $0.66980-0.81696$ ) but a poor test for the discrimination for the age group 1 (ROCAUC $0.6118,95 \%$ CI 0.38846-0.83514) and age group (ROC-AUC 2 0.6761, 95\% CI 0.59038- 0.76185) (Fig.1). 

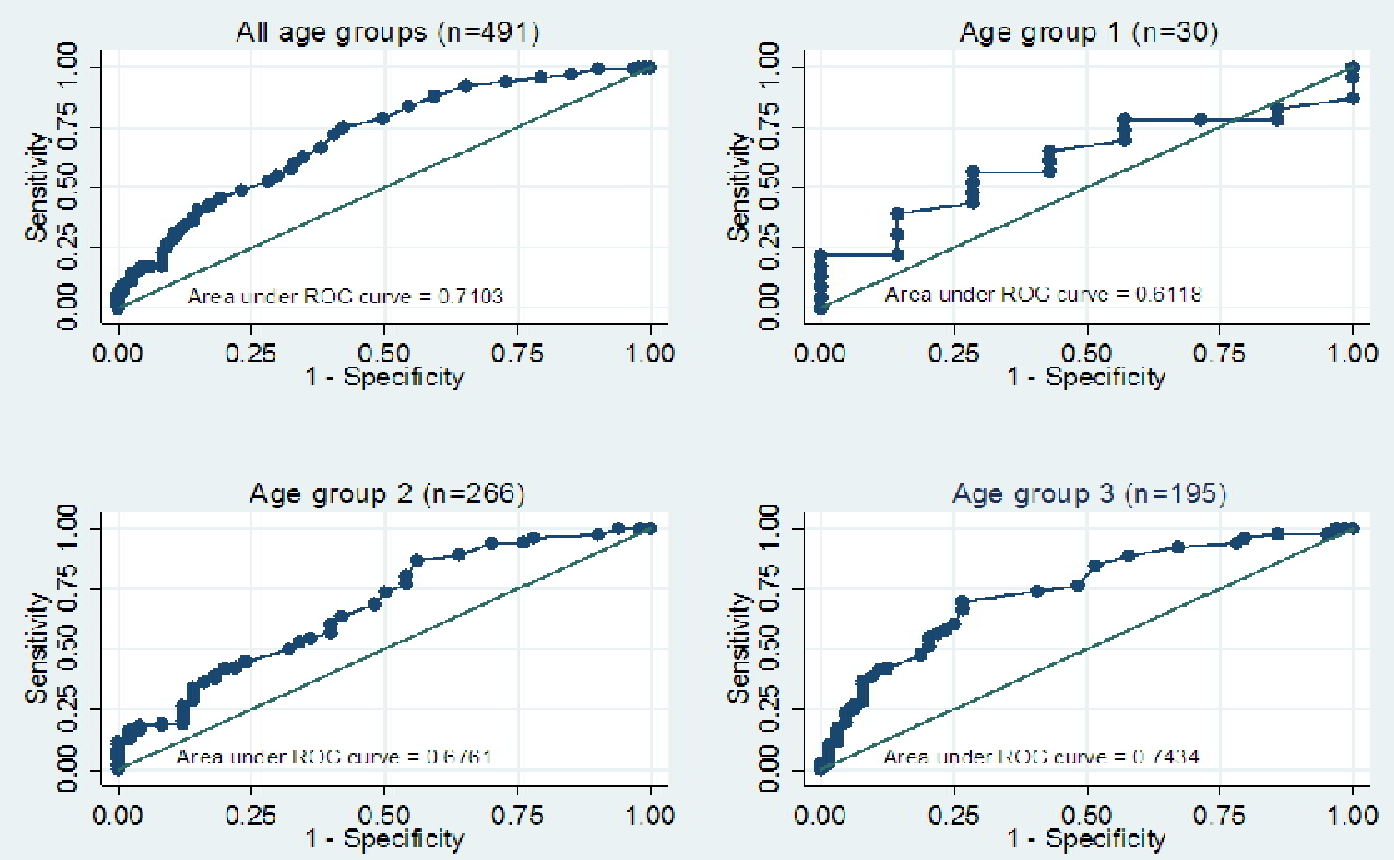

Figure(1): ROC-AUC for AMH prediction of cancelled and completed cycle

In the present study, we examined biomarkers and antral follicular count under each age group according to the quartiles of AMH. Table 3 shows the lowest and highest quartiles. We observed that, in all age groups, AMH and AFC tended to increase with increasing quartiles of $\mathrm{AMH}$ and FSH level tends to decrease. Also, women in advanced age group (age group 3)showed the lowest AMH level and antral follicular count, and showed the highest FSH level relative to the other age groups. The women in the advanced age group with the highest AMH quartile showed significantly higher $\mathrm{AMH}$ and AFC than those in women in the lowest AMH quartile (Table 3).

\section{Table (3): Patients' characteristics according to age and AMH level}

\begin{tabular}{|c|c|c|c|c|c|c|c|c|c|}
\hline \multirow{2}{*}{$\begin{array}{c}\text { Groups } \\
\text { Parometers } \\
\mathrm{AMH}\end{array}$} & \multicolumn{3}{|c|}{$\begin{array}{c}\text { Group 1: age 20-29 } \\
\qquad(n=30)\end{array}$} & \multicolumn{3}{|c|}{$\begin{array}{l}\text { Group 2: age 30-39 } \\
\qquad(n=266)\end{array}$} & \multicolumn{3}{|c|}{$\begin{array}{l}\text { Group 3: age 40-45 } \\
\qquad(n=195)\end{array}$} \\
\hline & $\begin{array}{l}\text { Low } \\
\text { AMH } \\
(\mathrm{n}=8)\end{array}$ & $\begin{array}{l}\text { High } \\
\text { AMH } \\
(\mathrm{n}=6)\end{array}$ & $\begin{array}{l}\text { P- } \\
\text { value }\end{array}$ & $\begin{array}{l}\text { Low } \\
\text { AMH } \\
(\mathrm{n}=73)\end{array}$ & $\begin{array}{l}\text { High } \\
\text { AMH } \\
(\mathrm{n}=6)\end{array}$ & P-value & $\begin{array}{l}\text { Low } \\
\text { AMH } \\
(n=73)\end{array}$ & $\begin{array}{l}\text { High } \\
\text { AMH } \\
(\mathrm{n}=45)\end{array}$ & P-value \\
\hline Age(years) & 25.5 & 26.3 & NS & 36.2 & 35.2 & 0.0141 & 42.43 & 41.95 & NS \\
\hline $\mathrm{AMH}$ & 1.41 & 10.43 & $\begin{array}{l}0.001 \\
9\end{array}$ & 0.86 & 5.88 & 0.0001 & 0.63 & 4.22 & 0.0001 \\
\hline FSH & 8.26 & 6.85 & NS & 9.71 & 6.77 & 0.0001 & 9.84 & 7.73 & NS \\
\hline AFC & 6.25 & 12.67 & $\begin{array}{l}0.023 \\
3\end{array}$ & 3.71 & 9.15 & 0.0001 & 2.6 & 6.51 & 0.0001 \\
\hline
\end{tabular}


The logistic regression, the odd ratio of having a cycle cancellation for young patients (20-39) with level of AMH of 2 pmoL/1 or less was double the odds for those with AMH level more than 2 $\mathrm{pmoL} / \mathrm{l}$ in the same age group (age group $1 \& 2)(\mathrm{p}=0.018)$. The odds of having a cancelled cycle for women of advanced reproductive age (40-45) with AMH (2 $\mathrm{pmoL} / \mathrm{l}$ or less) is 5 times was more than those with AMH level more than 2
pmoL/l in the same age group (age group 3 ). When adding FSH and AFC to the logistic regression, the prediction of cycle cancellation is only significant for women of advanced reproductive age (i.e. group 3). Patients with AMH level of $2 \mathrm{pmoL} / 1$ or less are 4 times more likely to have a cancelled cycle and patients with FSH level more than 10 are 3 times more likely to have a cancelled cycle for patients who are 40-45 years old(Table 4).

Table (4): Logistic regression analysis of the variables, for the prediction of cycle cancellation

\begin{tabular}{|c|c|c|c|c|c|c|}
\hline \multirow{2}{*}{ Groups } & \multicolumn{3}{|c|}{$\begin{array}{c}\text { Group 1\&2: age 20-39 } \\
(n=296)\end{array}$} & \multicolumn{3}{|c|}{ Group 3: age 40-45 $(n=195)$} \\
\hline & $\begin{array}{l}\text { Odd } \\
\text { ratio }\end{array}$ & $95 \% \mathrm{CI}$ & $\begin{array}{c}\mathrm{P}- \\
\text { value }\end{array}$ & $\begin{array}{l}\text { Odd } \\
\text { ratio }\end{array}$ & $95 \% \mathrm{CI}$ & P-value \\
\hline \multicolumn{7}{|l|}{$\begin{array}{l}\text { Univariate } \\
\text { analysis }\end{array}$} \\
\hline $\mathrm{AMH}$ & 2.06 & $1.131-3.759$ & 0.018 & 5.06 & $2.235-11.479$ & 0.0001 \\
\hline \multicolumn{7}{|l|}{$\begin{array}{l}\text { Multivariate } \\
\text { analysis }\end{array}$} \\
\hline AMH & 1.83 & $0.945-3.551$ & NS & 4.35 & $1.801-10.538$ & 0.001 \\
\hline FSH & 1.42 & $0.365-1.343$ & NS & 3.31 & $0.149-0.608$ & 0.001 \\
\hline $\mathrm{AFC}$ & 1.09 & $0.480-1.740$ & NS & 1.29 & $0.314-1.887$ & NS \\
\hline
\end{tabular}

AMH, anti-müllerian hormone; FSH, follicle stimulating hormone; AFC, antral follicle count .

Statistically significant: $\mathrm{P}<0.05$, NS: not significant.

The AMH cut off point of $2 \mathrm{pmoL} / 1$ was chosen to be consistent with the literature which defines this point as a point of absolute poor response

\section{DISCUSSION}

In this study, we investigated the use of $\mathrm{AMH}$ and other biomarkers in the detection of cycle cancellation during ART treatments (ICSI). ART are expensive for healthcare systems or
(Calamera et al., 2013). Similarly, the cut off point for FSH is 10 (Le et at., 2013) and the cut off point for AFC is $12(\mathrm{Ng}$ et al., 2000 and Broekmans et al., 2012). private practices and represent a stressful situation for the couple, therefore, the necessity exists for optimization of the evaluation of the ovarian reserve to minimize the uncertainty of the outcome of ART procedures (Calamera et al., 2013). 
Broekmans stated that female age is considered the main predictor of ovarian aging, there is a decline in fertility after the age of thirty years which will accelerates thereafter. The rate of decline in fertility may vary considerably between women of the same age. The availability of a test capable of providing reliable information regarding a woman's individual ovarian reserve within certain age category would enable to individually tailor treatment protocols (Broekmans et al., 2012).

La Marca stated that the correlation with oocyte yield and AMH is better than the association observed for the age of the patient, day3FSH, estradiol, or inhibin B (La Marca et al., 2010).Hendriks and Broer stated that the number of antral follicles represents a good estimator of the primordial follicle pool and, therefore, of the quantitative aspect of the ovarian reserve (Hendriks et al., 2007, and Broer et al., 2009).

In the current study, we investigated the value of morphometric and basal endocrine parameters during the follicular phases as predictors of cycle cancellation. We found significant evidence that AMH is a reliable predictor of cycle cancellation in advanced age women (>40 years old). In the present study, the patients were divided into three groups based on their age. AMH was found to be a fair test to discriminate between completed and cancelled cyclesin advanced age women (>40 years old). Also, we found significant relationship between low level of $\mathrm{AMH}$ and cycle cancellation in advanced age women ( $>40$ years old).Our results are in line with those previously reported by other author (Kailasam) showing that $\mathrm{AMH}$ is a useful marker for predicting cycle cancellation, and poor response to ovarian stimulation (Kailasam et al., 2004).Broerstated that AMH represents a better predictor than the other classically associated parameters such as FSH, estradiol and age (Broer et al., 2009). Interestingly, our data shows the special importance of serum AMH in women aged $>40$. The chance of cycle cancellation in young patients (20-39) with low level of AMH aretwo times more likely than other women in the same age group. For the women in advanced age group, the likelihood of having a cancelled cycle for women with low AMH is five times more than other women in the same age group. When having other predictors (FSH and AFC) in the analysis, the $\mathrm{AMH}$ still predicts cycle cancellation for women in advanced age group. High FSH level also shows significant prediction of cycle cancellation but only for women in advanced age group.

\section{CONCLUSION}

According to results observed in this study, serum AMH levels can be used as a fair predictor test for cycle cancellation especially in older age group patients. Its use can help to individualize treatments protocols and counselling in different age groups.

\section{CONFLICT OF INTEREST}

No conflict of interest was declared by the authors.

\section{REFERENCES}

1. Bentzen G, Forman L, Pinborg A, Lidegaard ?, Larsen C, Friis-Hansen L, Johannsen $T$ and Nyboe A. (2012): Ovarian reserve parameters: a comparison between users and 
non-users of hormonal contraception. Reprod. Biomed Online, 25(6): 612-19.

2. BroekmansF,BroerS,FauserB andMacklonN (2012): Prognostic testing for ovarian reserve. Textbook of assisted reproductive techniques. 4th edition. Ed, Gardner, D. Weissman, A. Informa Healthcare, 2: 40-8.

3. Broer L, Mol B, Hendriks Dand BroekmansF (2009): The role of antimullerian hormone in prediction of outcome after IVF: comparison with the antral follicle count. FertilSteril.;91:705-14. [PubMed].

4. Calamera P, Mariano G, Buffone G, De Vincentiis S, Rey $R$ and Olmedo $S$ (2013): Serum AMH level can predict the risk of cycle cancellation and the chances of good ovarian response independently of patient's age or FSH. JBRA Assisted Reproduction, 17 (2):101-8.

5. Hendriks J, Kwee J, MolW, Velde Rand Broekmans J (2007): Ultrasonography as a tool for the prediction of outcome in IVF patients: a comparative meta-analysis of ovarian volume and antral follicle count. FertilSteril., 87:764-75.

6. Kailasam S, Keay P. Ford W and Jenkins M (2004): Defining poor ovarian response during IVF cycles, in women aged <40years, and its relationship with treatment outcome. Hum Reprod., 19: 1544-7.

7. Kelsey W, WrightP, Nelson M, Anderson Aand Wallace H (2011): A validated model of serum anti-Müllerian hormone from conception to menopause. PLoS One, 6(7): e22024.

8. Kligman I and Rosenwaks $Z$ (2001): Differentiating clinical profiles: predicting good responders, poor responders, and hyperresponders. FertilSteril., 76:1185-90.
9. La Marca A and Sunkara SK (2014): Individualization of controlled ovarian stimulation in IVF using ovarian reserve markers: from theory to practice. Hum Reprod. Update, 20: 124-40.

10. La Marca A, Sighinolfi G, Radi D, Argento C, Baralchi e, Artenisio A, Stabile G and Valope A (2010): Anti- Mullatian hormone $(\mathrm{AMH})$ as a predictive marker in assisted reproductive technique (ART). Hum Reprod Update, 16: 113-30.

11. Li W, Lee C, Lau Y, Yeung S, Ho C and Ng H (2013): Role of baseline antral follicle count and anti-Mullerian hormone in prediction of cumulative live birth in the first in vitro fertilization cycle: a retrospective cohort analysis. PLoS One, 8: e61095. [PMC free article] [PubMed].

12. Ng H, Tang $S$ and Ho C (2000): The significance of the number of antral follicles prior to stimulation in predicting ovarian responses in an IVF programme. Hum Reprod., 15:1937-42. [PubMed].

13. Ubaldi M, Rienzi L, Ferrero S, Baroni E, Sapienza F, Cobellis Land Greco E (2005): Management of poor responder in IVF. Reprod Biomed Onlin,10:235-46.

14. Van HoutenL, Themmen Pand VisserA (2010): Anti-Mullerian hormone: regulator and marker of ovarian function Ann. Endocrinol., 71: 191-7. 


\section{تقييم دور هرمونات كدليل موثوق به لإلغاء الدوره التحفيزيه

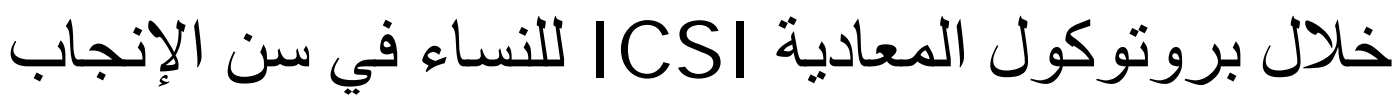 المتقدمة المانة}

بثينه خليل قريو* ، اسماعيل محمد الفورتيه* ، حنان الجبو*، نهله (براهيم بيت المال***

$$
\begin{aligned}
& \text { *المركز الوطني لمعالجه العقم كليه الطب البشري - جامعه مصراته لـيبيا } \\
& \text { **باحثه احصائيه جامعه كاليدونيا جلاسكو - جامعه جلاسكو ـ المملكه المتحدة }
\end{aligned}
$$

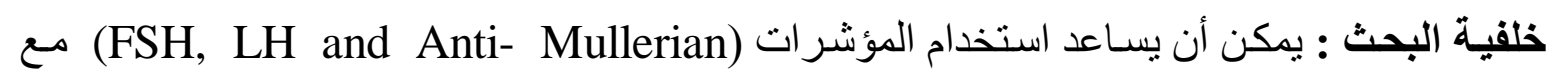
احتيـاطي المبيض (ORT) و عمر المـراه علي اتخـاذ قرار إلغـاء استكمال الدورة التحفيزيـه خـلال بروتوكول الحقن المجهري في الفئات العمرية المختلفة. الهدف من البحث: لتقييم دور هرمون مضـاد مولليريان كمؤشر لإلغاء الدوره التحفيزيه في النساء خلالبروتوكول عدائيه الحقن المجهري.

المشـاركات والأسـاليب: دراسـه استعاديه وصفيه لعدد اجو\(حالـه) ـ الحـالات تلقت تحفيز المبيض

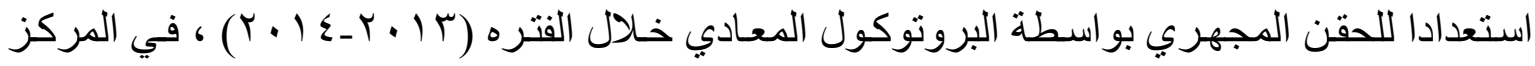

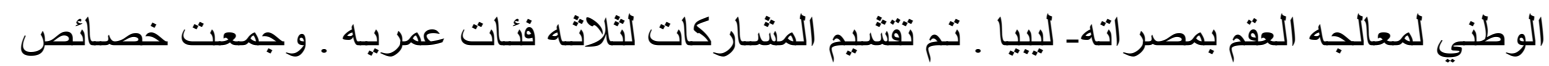

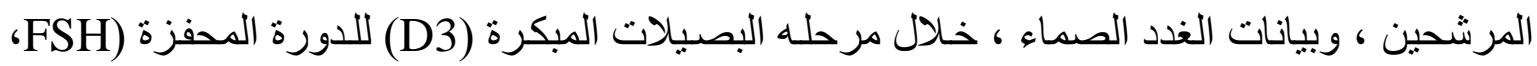

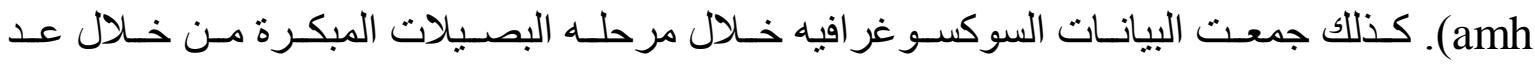

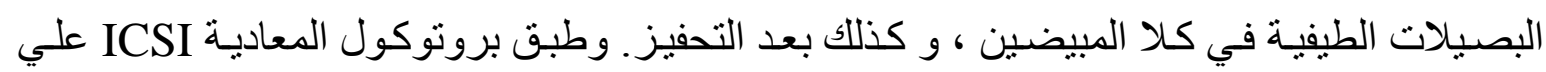
جميع المرضي من مختلف الفئات العمرية.

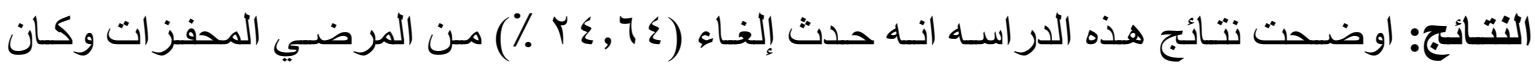

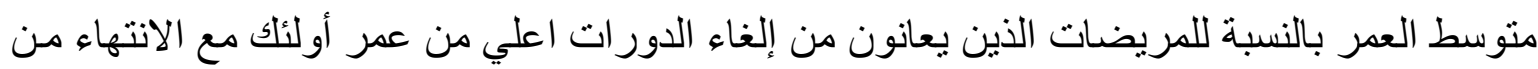

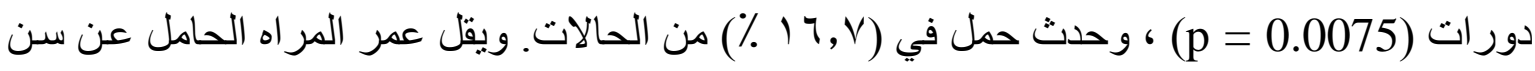

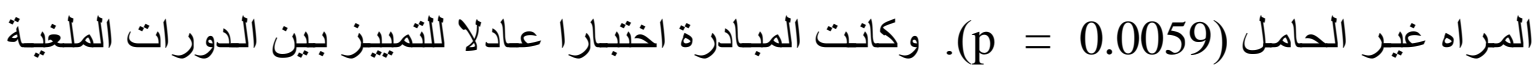

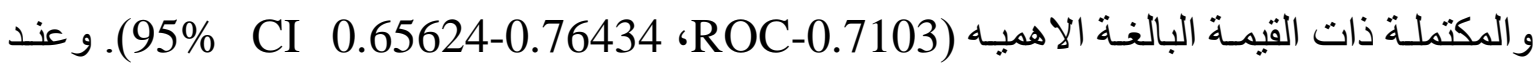

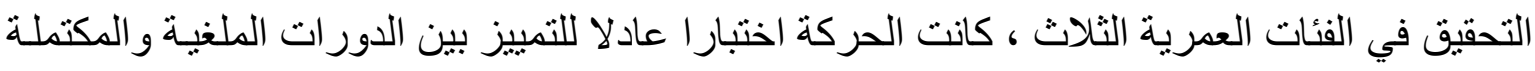
للفئات العمرية > 9 سنهمن العمر و كان هرمون AMH هو الاكثر اهميه في المؤشرات الثناثث. 
الاستنتاج: هرمون Anti-Mullerian مؤشر موثوق بـه لإلغـاء الدوره التحفيزيه خـلال بروتوكول ICSI المعادية

التوصيات: يمكن استخدام مستويات هرمون AMH كاختبار التوقع العادل لإلغاء الدوره التحفيزيه خاصـه

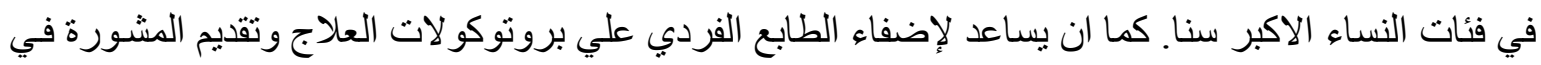

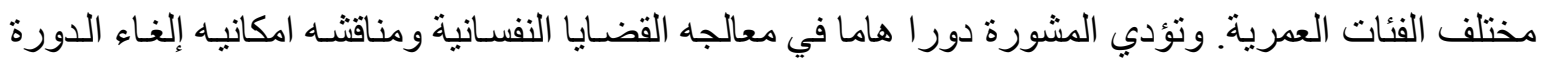
التحفيزيه وذللك للمساعدة في تخفيف التكلفه العلاجيه. 